NBER WORKING PAPER SERIES

\title{
THE DIFFUSION OF THE INTERNET AND THE GEOGRAPHY OF THE DIGITAL DIVIDE IN THE UNITED STATES
}

\author{
Shane Greenstein \\ Jeff Prince \\ Working Paper 12182 \\ http://www.nber.org/papers/w12182 \\ NATIONAL BUREAU OF ECONOMIC RESEARCH \\ 1050 Massachusetts Avenue \\ Cambridge, MA 02138 \\ April 2006
}

Forthcoming in R. Mansell, C. Avgerou, D. Quah and R. Silverstone (eds) Oxford Handbook on ICTs. Oxford University Press. The views expressed herein are those of the author(s) and do not necessarily reflect the views of the National Bureau of Economic Research.

(C)2006 by Shane Greenstein and Jeff Prince. All rights reserved. Short sections of text, not to exceed two paragraphs, may be quoted without explicit permission provided that full credit, including $\odot$ notice, is given to the source. 
The Diffusion of the Internet and the Geography of the Digital Divide in the United States Shane Greenstein and Jeff Prince

NBER Working Paper No. 12182

April 2006

JEL No. O3, L8, R0

\begin{abstract}
Shane Greenstein
Kellogg School of Management

Northwestern University

2001 Sheridan Road

Evanston, IL 60208-2013

and NBER

greenstein@kellogg.northwestern.edu

Jeffrey Prince

Cornell University

433 Warren Hall

Ithaca, NY 14853

itp35@cornell.edu
\end{abstract}

$\underline{\text { ABSTRACT }}$

This paper analyses the rapid diffusion of the Internet across the United States over the past decade for both households and firms. We put the Internet's diffusion into the context of economic diffusion theory where we consider costs and benefits on the demand and supply side. We also discuss several pictures of the Internet's physical presence using some of the current main techniques for Internet measurement. We highlight different economic perspectives and explanations for the digital divide, that is, unequal availability and use of the Internet. 


\section{Introduction}

The Internet is unlike any communications network that came before it. It is a complex technology embedded in a multi-layered network, and many different participants operate its pieces. The National Science Foundation (NSF) began to commercialize the Internet in 1992. Within a few years there was an explosion of commercial investment in Internet infrastructure in the United States. By October of 2003, 61.5 million (54.6 per cent) homes in the United States had Internet connections (NTIA 2004).

As with any new technology, the diffusion of the Internet follows predictable regularities. For example, it always takes time to move a frontier technology from a small cadre of enthusiastic first users to a larger majority of potential users. In this sense the economic patterns found throughout the early diffusion of the Internet are general. The diffusion of the Internet also possesses some unique features. It has thus far proceeded in two waves. There is a clear difference between low-speed/dial-up connection and high-speed/hard-wire connection. In the early 1990s, those with dial-up connection were considered at the frontier, but by the turn of the millennium, dial-up connection had clearly become a nonfrontier technology, with the new frontier consisting of high-speed connections, mainly through xDSL and cable.

This experience raises pressing policy issues. A pessimistic view emerged in the mid 1990s, one that became affiliated with the notion labelled 'the digital divide.' It forecast that the Internet was diffusing disproportionately to urban areas with their 
complementary technical and knowledge resources for supporting personal computers (PCs) and other computing, leaving rural areas behind. A related recent concern highlights the uneven use of frontier technologies in the second wave, in this case, broadband access and related complementary applications.

This chapter provides an overview of the economic processes underlying the geographic digital divide. This involves two goals - to analyse a specific phenomenon, and to communicate general lessons. We provide a survey of the growing and detailed literature concerning the diffusion of the Internet in the United States during its first two waves. This is a specific story told about a specific technology in a particular time period, and, at the same time, throughout this chapter we use this story to understand broader questions about the economic workings of diffusion processes. In addition, we will conceive the Internet as a general purpose technology (GPT), using it to build a framework about the economic determinants of its diffusion.

\section{Brief history of the Internet}

The digital divide did not arise overnight, nor did the Internet. What became the Internet began in the late 1960s as a research project of the Advanced Research Projects Administration of the United States Department of Defense, the ARPANET. From these origins sprang the building blocks of a new communications network. By the mid1980s, the entire Internet used Transmission Control Protocol/Internet Protocol (TCP/IP) packet-switching technology to connect universities and defence contractors.

Management for large parts of the Internet was transferred to the National 
Science Foundation, or NSF, in the mid-1980s. Through NSFNET, the NSF was able to provide connection to its supercomputer centres and a high-speed backbone, from which to develop the Internet. Since use of NSFNET was limited to academic and research locations, Alternet, PSInet, and SprintLink developed their own private backbones for corporations looking to connect their systems with TCP/IP (Kahn 1995).

By the early 1990s the NSF had developed a plan to transfer ownership of the Internet out of government hands and into the private sector. When NSFNET was shut down in 1995, only for-profit organizations were left running the commercial backbone. Thus, with the Internet virtually completely privatized, its diffusion path within the United States was dependent on market forces and economic incentives (Greenstein 2005).

Unlike many other technologies embedded in a single type of durable good, the Internet is a malleable technology whose form is not fixed across time and location. As with malleable GPTs, to create value, the Internet must be embedded in investments at firms that employ a suite of communication technologies, TCP/IP protocols, and standards for networking between computers. Often organizational processes also must change to take advantage of the new capabilities.

\section{The diffusion process}

Because of the unusual origins of the Internet, it is not immediately obvious that economic theories of diffusion provide an effective guide for analysing the geographical diffusion of the Internet. According to such economic diffusion theory, the rate of 
adoption of a new technology is jointly determined by consumers' willingness to pay for the new product, and suppliers' profitability from entering the new market. Both typical users and typical suppliers change over time. We consider each of these factors in turn.

\section{Standard diffusion analysis}

We begin our analysis with simple definitions. Any entity (household, individual, or firm) is considered to be connected to the Internet if it has the capability of communicating with other entities (information in and/or information out) via the physical structure of the Internet. We will defer discussion about connections coming at different speeds (56K dial up versus broadband) and from different types of suppliers (AOL versus a telephone company).

With regard to consumers, it is the heterogeneity of adopters that generally explains differences in the timing of adoption (Rogers 1995). When a technology first reaches the frontier, a group of risk-taking innovators adopts first and, over time, the technology moves down the hierarchy to mainstream users seeking pragmatic gains. If these groups are not evenly dispersed geographically, there will be an uneven rate of adoption across regions of the country.

In addition, a good deal of heterogeneity in user response in this case is the direct result of another technology's diffusion - that of PCs. The Internet is a 'nested innovation' in that heterogeneity among its potential adopters depends heavily on the diffusion process of PCs (Jimeniz and Greenstein 1998). In addition to this nesting, 
within the class of PC users there are also differences in their willingness to experiment and the intensity of their use. ${ }^{2}$ There are differences in types of adopters across regions in terms of the following five attributes of a new technology widely considered as the most influential for adoption speed across different types of users: relative advantage, compatibility, complexity, trialability, and observability. Any increase in the relative advantage over the previous technology, the compatibility of the new technology with the needs of potential adopters, the ability of adopters to experiment with the new technology, or the ability of users to observe the new technology will speed up the diffusion process. Similarly, any decrease in technological complexity will also speed up the diffusion process (Rogers 1995).

The Internet has relative advantages along many dimensions. It provides written communication faster than postal mail, allows for purchases online without driving to the store, and dramatically increases the speed of information gathering. The Internet is also easy to try out (perhaps on a friend's PC or at work), easy to observe, and compatible with many consumer needs (information gathering, fast communication); and its complexity has been decreasing consistently.

The above attributes hold across the United States, but the degree to which they hold is not geographically uniform. Specifically, we see differences between rural and urban areas. For example, people living in rural areas might find greater relative advantage since their next-best communication is not as effective as that of their urban counterparts. Also, they might find the Internet more difficult to try or observe, and possibly more complex if they have less exposure to or experience with PCs. 


\section{GPT framework}

Within general diffusion theory there can be much dispute as to why the adoption of a new technology is actualized in a specific way. Here, we apply a GPT framework to our study of the diffusion of the Internet. Bresnahan and Trajtenberg (1995) define a GPT as a capability whose adaptation to a variety of circumstances raises the marginal returns to inventive activity in each of these circumstances. GPTs are often associated with high fixed costs and low marginal costs to use. The invention of the Internet follows this pattern, in the sense that the technology was largely invented and refined by the early 1990s (Bresnahan and Greenstein 2001).

The GPT framework further predicts that additional benefit from the technology comes from co-invention of additional applications. Co-invention costs are the costs affiliated with customizing a technology to particular needs in specific locations at a point in time. These costs can be quite low or high, depending on the idiosyncrasy and complexity of the applications, as well as the economies of scale within locations. They may also depend on regulatory rules over access to network. For example, in the case of dial-up access, Internet service providers (ISPs) faced comparatively low incremental costs because they were complementary to the telephone system. In contrast, particularly in the case of broadband, provision of the Internet in a region involves high fixed costs of operating switches, lines, and servers.

We expect to see firms wishing to minimize fixed costs or exploit economies of scale by serving large markets. Also, the cost of 'last mile' connection (for example, 
$\mathrm{xDSL}$ or cable) in rural areas is far greater due to their longer distance from the backbone. This basic prediction frames much of the research on the diffusion of the Internet. There will necessarily be a margin between those who adopt and those who do not. What factors are correlated with the observed margin? We can divide these factors into those associated with raising or lowering the costs of supply or the intensity of demand.

\section{The marginal PC adopter}

According to the NTIA (2004) study, as of 2003, approximately 61.8 per cent of American homes owned a PC, with Internet participation rates at 54.6 per cent. These adoption rates suggest that the diffusion of each technology is moving into the late majority category of adopters, though there is considerable disagreement about how to portray the rate of adoption for the remaining households. As mentioned above, the Internet is a nested innovation whose adoption at home strongly depends on adoption of a PC. ${ }^{3}$ Since the vast majority ( 87.6 per cent) of PC owners have home Internet access, the marginal Internet adopter looks very similar to the marginal PC adopter and, related, it is natural to hypothesize that the determinants of adoption among non-adopters will differ from its determinants in the late 1990s.

Prince (2005) conducts a structural analysis of the demand for (desktop) PCs in 2001 in the United States. A main objective of the paper is to model two very different looking demand curves - PC demand for households already owning a PC (repeat purchasers), and PC demand for households that have never owned a PC (first time purchasers). His data indicate a large difference between these two groups: the 
likelihood of buying a new PC in 2001 was more than two times greater for a repeat purchaser than for a first time purchaser. The demand for first time purchasers is especially relevant since it represents the marginal adopters for PCs, and therefore, strongly resembles the marginal adopters of the Internet.

In his paper, Prince describes three main determinants of the 'divide' in PC ownership: heterogeneity (in the marginal utility of PC quality and PC holdings), startup costs, ${ }^{4}$ and dynamics. His results indicate that the marginal utility of PC quality is strongly increasing in income and education, and strongly decreasing in age. Further, forward-looking behavior also affects the demand for PCs. As prices fall and quality rises over time, the decision about whether to buy a new PC is complicated by the decision of when to buy a new PC. The results show that households' expectations about what PCs will be available in the future affect current demand. Finally, regarding the two demand curves, the paper finds that first time purchasers are more price sensitive than repeat purchasers, and face large start-up costs.

These results show that, as the diffusion of the PC moves deeper into mainstream use, the marginal PC adopter is a household with low marginal value for PC quality, high start-up costs, significant price sensitivity, and potential difficulty in determining when (not necessarily if) to buy. These findings show why the early experience in the adoption of the Internet provides little help for understanding user adoption in later periods. Quite a different set of factors shapes later adoption than shaped early adoption. 


\section{Demand by households}

Data from 2001 (NTIA 2002) show Internet usage to be positively correlated with household income, employment status, and educational attainment. With regard to age, the highest participation rates were among teenagers, while Americans in their prime working ages (20-50 years of age) were also well connected (about 70 per cent) (NTIA 2002). Although there did not appear to be a gender gap in Internet usage, there did appear to be a significant gap in usage between two widely defined racial groups: (1) whites, Asian Americans, Pacific Islanders (approximately 70 per cent); and (2) Blacks and Hispanics (less than 40 per cent) (NTIA 2002). Much of this disparity in Internet usage can be attributed to observable differences in education and income. For example, at the highest levels of income and education there are no significant differences in adoption and use across ethnicities.

In general, Internet and PC demanders have much in common, and differences in adoption rates across the above variables are similar for both technologies. However, specific to the Internet, a great deal of literature points to a digital divide between rural and urban areas, contending that rural residents are less connected to the Internet than urban ones. Some argue that rural citizens are less prone to use computers and digital networks because of exacerbating propensities arising from lower income, less education, and less technological skills (on average) than those living in the city. The evidence for this hypothesis is mixed, however, with many rural farm households using the Internet at high rates (USDA 2000). In addition, over the two-year span from 1998 to 2000 , Internet access went from 27.5 per cent to 42.3 per cent in urban areas, 24.5 per cent to 37.7 per cent in central cities, and 22.2 per cent to 38.9 per cent in rural areas. 
Thus, there was at least a narrowing of the gap in participation rates between rural and urban areas; and there certainly was no evidence of the gap widening on any front. ${ }^{5}$

Furthermore, when we divide American geography into three sections - rural, inner city urban, and urban (not inner city) - we see lower participation in the first two categories; inner city participation also being low potentially due to a greater percentage of citizens with lower income and education levels. With the higher concentration of Blacks and Hispanics in the inner city, there then arises the correlation between education and income and socioeconomics. As we previously stated, ethnicity is not the cause of lower adoption rates; instead, lower education and income levels, which in turn are caused by socioeconomic factors, create lower adoption rates in the inner cities (Strover 2001). There is also increasing evidence that there is considerable variance in the abilities and skills to take advantage of what the technology has to offer. While this variance correlates somewhat with socioeconomic factors, it also raises a distinct set of issues. $^{6}$

It has been argued that the benefits of adoption are greater for rural areas, because rural residents can use the Internet to compensate for their distance from other activities. Adopting the Internet improves retail choices, information sources, education options, and job availability more than for urban residents (Hindman 2000; Sinai and Waldfogel 2004). However, these benefits may or may not be translated into actual demand, depending on many factors, such as income, education, local support services, or a host of social factors. 


\section{Demand for business purposes}

Businesses adopt different aspects of Internet technology for a variety of reasons. In the standard framework for analysing diffusion, the decision to adopt or reject the Internet falls within three categories: (1) optional, where the decision is made by the individual; (2) collective, where it is made by consensus among members; or (3) authoritative, where it is made by a few people with authority (Rogers 1995). For businesses, the decision process generally falls under one of the latter two categories.

Business adoption of the Internet came in a variety of forms. Implementation for minimal applications, such as email, was rather straightforward by the late 1990s. It involved a PC, a modem, a contract with an ISP and some appropriate software. In contrast, investment in the use of the Internet for an application module in a suite of Enterprise Resource Planning (ERP) software, for example, was anything but routine during the latter half of the 1990s. Such an implementation included technical challenges beyond the Internet's core technologies, such as security, privacy, and dynamic communication between browsers and servers. Usually organizational procedures also changed.

A further motivating factor will shape business adoption: competitive pressure. As Porter (2001) argues, there are two types of competitive motives behind Internet adoption. First, the level of 'table stakes' may vary by region or industry. That is, there may be a minimal level of investment necessary just to be in business. Second, there may be investments in the Internet that confer competitive advantage vis-à-vis rivals. Once again, these will vary by location, industry, and even the strategic positioning of a 
firm (for example, price leader, high service provider) within those competitive communities. The key insight is that such comparative factors shape competitive pressure.

Several recent studies look empirically at determining factors for Internet adoption by firms and the possible existence of a digital divide among them. Premkumar and Roberts (1999) test the former by measuring the relevance of ten information technology attributes for the adoption rate of small rural businesses. The ten attributes are: relative advantage, compatibility, complexity, cost-effectiveness, top management support, information technology expertise, size, competitive pressure, vertical linkages, and external support. They found that relative advantage, costeffectiveness, top management support, competitive pressure, and vertical linkages were significant determinants for Internet adoption decisions.

Forman (2005) examines the early adoption of Internet technologies at 20,000 commercial establishments from a few select industries. He concentrates on a few industries with a history of adoption of frontier Internet technology and studies the microeconomic processes shaping adoption. He finds that rural establishments were as likely as their urban counterparts to participate in the Internet and to employ advanced Internet technologies in their computing facilities to enhance their computing facilities. He attributes this to the higher benefits received by remote establishments, which otherwise had no access to private fixed lines for transferring data. Forman, Goldfarb, and Greenstein (2002, 2003a,b) measured national Internet adoption rates for medium and large establishments from all industries. ${ }^{7}$ They distinguish between two purposes 
for adopting, one simple and the other complex. The first purpose, labelled participation, relates to activities such as email and web browsing. This represents minimal use of the Internet for basic communications. The second purpose, labelled enhancement, relates to investment in frontier Internet technologies linked to computing facilities. These latter applications are often known as e-commerce, and involve complementary changes to internal business computing processes. The economic costs and benefits of these activities are also quite distinct; yet, casual analysis in the trade press tends to blur the lines between the two.

Forman, Goldfarb, and Greenstein examined business establishments with 100 or more employees in the last quarter of 2000. They show that adoption of the Internet for purposes of participation is near saturation in most industries. With only a few exceptional, laggard industries, the Internet is everywhere in medium to large business establishments. Their findings for enhancement contrast sharply. There is a strong urban bias towards the adoption of advanced Internet applications. The study concludes, however, that location, per se, does not handicap adoption decisions. Rather, the industries that 'lead' in advanced use of the Internet tend to be disproportionately located in urban areas.

They conclude that a large determinant of the location of the Internet in ecommerce was the preexisting distribution of industrial establishments across cities and regions. This conclusion highlights that some industries are more information intensive than others and, accordingly, make more intensive use of new developments in information technologies, such as the Internet, in the production of final goods and 
services. Heavy Internet technology user industries have historically been banking and finance, utilities, electronic equipment, insurance, motor vehicles, petroleum refining, petroleum pipeline transport, printing and publishing, pulp and paper, railroads, steel, telephone communications and tyres (Cortada 1996).

Forman, Goldfarb and Greenstein (2005) find evidence consistent with the 'urban leadership' hypothesis. In this view the infrastructure necessary for the geographic diffusion of the Internet, such as the equipment to enable high-speed Internet access, initially appeared to be difficult to deploy and use. Technically difficult technologies favour urban areas, where there are thicker labour markets for specialized engineering talent. Similarly, close proximity to thick technical labour markets facilitates the development of complementary service markets for maintenance and engineering services. Labour markets for technical talent were relevant to the diffusion of new technologies in the Internet. As with many high-tech services, areas with complementary technical and knowledge resources are favoured during the early use of technology.

These findings raise an open question. Early use of advanced technology favours growth in a few locations, such as Silicon Valley, the Boston area, or Manhattan - for a time at least, particularly when technologies are young. But will it persist? This depends on how fast the technology matures into something standardized that can be operated at low cost in areas with thin supply of technical talent.

Furthermore, complex Internet applications are linked to computing facilities, 
which are often known as e-commerce or e-business. Most often, these technologies involve inter-establishment communication and/or substantial changes to business processes. Cross-establishment Internet technologies, in contrast, represent Internet investments that involve communication among establishments within the value chain (for example, an extranet) or between an establishment and its end consumers. Forman, Goldfarb, and Greenstein (2005) hypothesize that geographically isolated establishments will have higher gross benefits from communicating with external suppliers and customers. Changes in location size and density will primarily influence costs (and not benefits) for communication within an establishment, but, on the other hand, such changes will influence both costs and benefits of communicating with external parties. They found evidence consistent with these views. That is, controlling for other factors, advanced Internet applications for communication outside the establishment had a higher propensity at rural establishments than Internet applications for communications within an establishment.

\section{Supply by private firms}

Since the Internet privatization in 1995 , private incentives have driven the supply side of Internet access. ISPs are divided into four classes: (1) transit backbone ISPs' (2) downstream ISPs; (3) online service providers (for example, AOL); and (4) firms that specialize in Web-site hosting. Provision incentives are profit based, and for a technology with significant economies of scale, profits will likely be higher in markets with high sales quantity. Thus, we see high numbers of ISPs in regions with high population concentrations (Downes and Greenstein 1998, 2002). 
The ISPs also decide on the services they provide (for example, value-added services) and the price at which they provide them. Greenstein $(2000 \mathrm{a}, \mathrm{b})$ highlights two types of activities other than basic access in which ISPs partake - high-bandwidth applications, and services that are complementary to basic access. He notes that differences in firm choices are due to 'different demand conditions, different quality of local infrastructure, different labor markets for talent,' or differing qualities of inherited firm assets.

Geography plays a role in these differences and can explain much of the variation in quality of access. We expect the local infrastructure quality to be higher in urban areas. The quality of ISP service will be higher there as well. In addition, rural ISPs often have less incentive to improve due to lack of competition, that is, they are the only provider in their area and thus there is little incentive to enhance their service.

\section{Supply by regulated telephone firms}

Every city in the United States has at least one incumbent local telephone provider. The deregulation of local telephony has been proceeding in fits and starts in many parts of the United States, since the AT\&T divestiture in the early 1980s. By the mid 1990s there had been significant attempts at and success in allowing competitive access providers to enter local markets to provide alternative local access paths, predominantly for data communications and large volume voice users in business. This movement is an attempt to increase the number of potential providers of local voice services beyond the monopoly incumbent and, in so doing, increase the competitiveness of markets for a variety of voice and data services. This form of deregulation became indirectly linked to 
the growth of broadband because the rules affecting telephony shaped the entry of potential broadband suppliers. Deregulation also had an indirect impact on the Internet's deployment because it altered the organization of the supply of local data services, primarily in urban areas. ${ }^{8}$

For our purposes here, the key question is, did the change in regulations shape the geographic diffusion of Internet access across the United States? The answer is almost certainly, yes, at least in the short run. However, the answer is more ambiguous in the long run. By the end of the millennium the largest cities in the United States had dozens of potential and actual competitive suppliers of local telephone service that interconnected with the local incumbent. By the end of 2000, over 500 cities in the United States had experience with at least a few competitive suppliers of local telephony, many of them focused on providing related Internet and networking services to local businesses, in addition to telephone service (New Paradigm Research Group 2000).

Prior to the commercialization of the Internet, decades of debate in telephony had already clarified some regulatory rules for interconnection with the public switch network for what the Federal Communications Commission (FCC) defined as an enhanced information service (Canon 2001). This set of rules applied to dial-up ISPs, but there would be considerable debate about applying them to broadband suppliers. In the dial-up era this set of rules eliminated some potential local delays in implementing this technology on a small scale. In treating ISPs as enhanced service providers and not as competitive telephone companies, the FCC did not pass on access charges to them, 
which effectively made it cheaper and administratively easier to be an ISP (Oxman 1999). ${ }^{9}$

The new competitor for the deregulated network is known as a Competitive Local Exchange Company, or CLEC for short. No matter how it is deployed, every CLEC has something in common: each offers phone service and related data carrier services that interconnect with the network resources offered by the incumbent provider (for example, lines, central switches, local switches). In spite of such commonalities, there are many claims in the contemporary press and in CLEC marketing literature that these differences produce value for end users. In particular, CLECs and incumbent phone companies offer competing versions of (sometimes comparable) DSL services and networking services.

Something akin to CLECs existed prior to the 1996 Telecommunications Act, the watershed federal bill for furthering deregulation across the country. These firms focused on providing high-bandwidth data services to business in high volume situations, as noted. After the passage of this bill, however, CLECs grew even more and quickly became substantial players in local networks, accounting for over twenty billion dollars a year in revenue in $2000 .{ }^{10}$ More to the point, CLECs became the centre of focus of the deregulatory movement. Many CLECs grew very rapidly and often took the lead in providing solutions to issues about providing the last mile of broadband, particularly to businesses and targeted households. In addition, many CLECs already were providing direct line (for example, T-1) services to businesses (as was the incumbent local phone company). After the 'telecom meltdown' in 2001, however, the 
biggest hopes for CLECs did not become reality. The market capitalization of the entire sector declined even as the number of customers served increased. Instead of developing new initiatives, many firms simply repackaged the Incumbent Local Exchange Providers services. ${ }^{11}$

The incumbent delivered services over the switch, and so did CLECs. In recognition of the mixed incentives of incumbents, regulators tried to set rules for governing the conduct of the transactions and these were challenged in court. As directed by the 1996 Telecommunications Act, this included setting the prices for renting elements of the incumbent's network, such as the loops that carried the DSL line. ${ }^{12}$ However, interpreting and implementing this area of regulation become one of the most contentious chapters in the United States' telecommunications policy. Legal challenges continued for some time, altering both the rules for unbundling and, eventually, the definition of the boundary between an information service and a telecommunications service. By 2005 Incumbent Local Exchange Providers were no longer obligated to make most DSL service available on a wholesale basis. ${ }^{13}$

Though short lived and constantly changing, this opportunity extended to virtually all cities with a population of more than 250,000 , and even to many cities with a population under 100,000. Very few rural cities, however, were afforded this opportunity except for those in the few states that promoted it. So, at the outset, if there were any effects at all, the entry of CLECs only moderately increased broadband supply (and in only urban locations, and in these, primarily to business), if at all. 
Due to the uneven availability of the Internet in some locations, local government authorities also intervened to speed deployment, during both the first (dialup) and second (broadband and wireless) waves of diffusion. Local governments acted as agents for underserved demanders by motivating broadband deployment in some neighbourhoods through select subsidies or the granting of rights of way (Strover and Berquist 2001). Public libraries often received help; the presence of a federal subsidy enables even the poorest rural libraries to have Internet access at subsidized rates (Bertot and McClure 2000). There is considerable variance in these practices over time and across locations, depending on local political circumstances and ever-shifting interpretations of national policy (see, for example, Gillett, Lehr, and Osario 2004).

Because CLECs did not play a large role in household markets, the second wave of diffusion, involving broadband, ultimately looked somewhat different from the first wave. ${ }^{14}$ Provision to business continued to involve a wide mix of providers, as described above. In contrast, both existing cable firms and incumbent local telephone companies became the dominant providers of high speed broadband services to homes in the United States. The only exceptions occurred in dense urban environments, such as Manhattan, where private carriers could provide connections to businesses as well as apartment buildings or condominiums (see Crandall and Waverman 2002).

Altogether, CLECs had two effects, on availability of Internet services and on costs/prices for services related to the Internet, such as broadband. During the diffusion of dial-up the costs of operating an ISP were brought down by the presence of CLECs in urban areas, a factor that surely sped up adoption. Due to the ambiguities of and 
frequent changes to regulatory rules, however, the effect of CLECs on prices in the second wave of diffusion is much more indirect and, therefore, more ambiguous.

\section{Mapping the Internet's dispersion}

A number of alternative methods have been devised for measuring the Internet's presence, or its adoption in a location. None is clearly superior, as they are all valid ways of measuring the diffusion of the technology across geographic regions.

\section{Backbone}

The commercial Internet is comprised of hubs, routers, high-speed switches, points of presence (POPs), and high-speed high-capacity pipes that transmit data. These pipes and supporting equipment are sometimes collectively referred to as the backbone. The backbone is comprised mostly of fibre-optic lines of various speeds and capacity. However, no vendor can point to a specific piece of fibre and call it 'backbone'. This label is a fiction, but a convenient one. Every major vendor has a network with lines that go from one point to another, but it is too much trouble to refer to it as 'transmission capacity devoted primarily to carrying traffic from many sources to many sources.'

Comparing the backbones in different regions is not straightforward. Its presence depends on many things such as population size, type of local industry, and other facets of local demand. Its maximum flow rate is only exploited at peak times, not most of the day, so statistics about capacity must be interpreted with care. Moreover, nobody would expect connection and bandwidth to be equally distributed across geographic space, so the appropriate benchmark for assessing the geographic dispersion 
of backbone is subject to debate. ${ }^{15}$

Despite this inherent interpretive ambiguity, there is intense policy interest in understanding the geography of commercially supplied backbone. There are concerns that some areas (for example, small towns) are underserved while others (for example, major cities) are served too well. There are also concerns that the industry is too concentrated, as well as nearly the opposite, that the competitive situation motivated firms to make impertinent and redundant investments.

One common theme in almost every article addressing the Internet's backbone is the following: a handful of cities in the United States dominate in backbone capacity, and, by extension, dominate first use of new Internet technology. Specifically, San Francisco/Silicon Valley, Washington, DC, Chicago, New York, Dallas, Los Angeles, and Atlanta account for the vast majority of backbone capacity (Moss and Townsend 2002, 2000). As of 1997, these seven cities accounted for 64.6 per cent of total capacity, and the gap between this group and the rest remained even during the intense deployment of new networks and capacity between 1997 and 1999. By 1999, even though network capacity had quintupled over the previous two years, the top seven still accounted for 58.8 per cent of total capacity.

In addition, the distribution of backbone capacity does not perfectly mimic population distribution, since metropolitan regions such as Seattle, Austin, and Boston have a disproportionately large number of connections (relative to their populations), whereas larger cities such as Philadelphia and Detroit have disproportionately fewer 
connections (Townsend 2001a, 2001b). Overall, the largest metropolitan areas are well served by the backbone, while areas such as the rural south have few connections (Warf 2001).

\section{Domain name registrations}

Domain names are used to help map intuitive names (such as www.northwestern.edu) to the numeric addresses computers use to find each other on the network. This address system was established in the mid-1990s and diffused rapidly along with the commercial Internet.

The leaders in total domain names are New York and Los Angeles; however, Chicago - normally considered along with New York and Los Angeles as a global city only ranks a distant fifth, far behind the two leaders. Furthermore, when ranking metropolitan areas according to domain names per 1,000 persons, of these three cities, only Los Angeles ranks among the top $20\left(17^{\text {th }}\right)$. The full ranking of domain name density indicates that medium-sized metropolitan areas dominate, while global cities remain competitive, and small metropolitan areas show very low levels of Internet activity (Townsend 2001a).

Moss and Townsend (2002) looked at the growth rate for domain name registrations between 1994 and 1997. They distinguish between global information centres, and global cities and find that global information centres, such as Manhattan and San Francisco, grew at a pace six times the national average. In contrast, global cities such as New York, Los Angeles, and Chicago grew only at approximately one to 
two times the national average.

Kolko (2000) examines domain names in the context of questioning whether the Internet enhances the economic centrality of major cities in comparison to geographically isolated cities. ${ }^{16} \mathrm{He}$ argues, provocatively, that reducing the 'tyranny of distance' between cities does not necessarily lead to proportional economic activity between them. That is, a reduction of communications costs between locations has ambiguous predictions about the location of economic activity in the periphery or the centre. Lower costs can reduce the costs of economic activity in isolated locations, but it can also enhance the benefits of locating coordinative activity in the central location. As with other researchers, Kolko presumes that coordinative activity is easier in a central city where face-to-face communications take place.

Kolko (2000) documents a heavy concentration of domain name registrations in a few major cities. He also documents extraordinary per capita registrations in isolated medium-sized cities. He argues that the evidence supports the hypothesis that the Internet is a complement to, not a substitute for face-to-face communications in central cities. He also argues that the evidence supports the hypothesis that lowering communication costs helps business in remote cities of sufficient size (that is, mediumsized, but not too small).

Hosts, Internet service providers, points of presence Measurements of host sites, ISPs, and POPs also have been used to measure the Internet's diffusion. Indeed, the growth of the Internet can be directly followed in the 
successive years of Boardwatch Magazine. The earliest advertisements for ISPs in Boardwatch Magazine appear in late 1993, growing slowly until mid-1995, at which point Boardwatch began to organize their presentation of pricing and basic offerings. There was an explosion of entries in 1995, with thousands being present for the subsequent few years. Growth only diminished after 2001.

Internet hosts are defined as computers connected to the Internet on a full-time basis. Host-site counting may be a suspect measurement technique due to its inability to differentiate between various types of equipment, and to the common practice of firms not to physically house Internet-accessible information at their physical location. Nevertheless, we do see results similar to those found with other measurement techniques, since, as of 1999, five states (California, Texas, Virginia, New York, and Massachusetts) contain half of all Internet hosts in the United States (Warf 2001).

Downes and Greenstein (2002) analyse the presence of ISPs throughout the Unites States. Their results show that, while low entry into a county is largely a rural phenomenon, more than 92 per cent of the United States population had access by a short local phone call to seven or more ISPs as of 1997. Strover, Oden, and Inagaki (2002) look directly at ISP presence in areas that have traditionally been underserved by communications technologies (for example, the Appalachian region). They examine areas in the states of Iowa, Texas, Louisiana, and West Virginia. They determine the availability and nature of Internet services from ISPs for each county and find that rural areas suffer significant disadvantages in relation to Internet service (see, also, Strover 2001). 
Measurements of POPs help to identify 'urban and economic factors spurring telecommunication infrastructure growth and investment' (Grubesic and O'Kelly 2002: 260). The POPs are locations where ISPs maintain communication equipment for network access. This is often a switch or router that allows Internet traffic to enter or proceed on commercial Internet backbones. Through POP measurement, Grubesic and O'Kelly derived similar results to those concerning the backbone, namely the top seven cities, Chicago, New York, Washington, DC, Los Angeles, Dallas, Atlanta, and San Francisco provide the most POPs. Furthermore, Boston and Seattle are emerging Internet leaders.

Grubesic and O'Kelly (2002) use POPs to measure which metropolitan areas are growing the fastest. Their data indicate that such areas as Milwaukee, Tucson, Nashville, and Portland saw major surges in POPs at the end of the 1990s. They provide several explanations for these surges: (1) proximity to major telecommunication centres (for example, Tucson and Milwaukee); (2) intermediation between larger cities with high Internet activity (for example, Portland); and (3) centralized location (for example, Nashville). Greenstein (2005) offers an additional interpretation of these findings, arguing that hub-and-spoke economics for networks in geographic space explains the general patterns for many advantageously-located large and medium sized cities.

\section{Content, E-commerce}

Zook $(2000,2001)$ proposes two additional methods for measuring the presence of the Internet. The first measures the Internet by content production across the United States. 
Zook (2000: 412; 2001) defines the content business as enterprises involved in the creation, organization, and dissemination of informational products to a global marketplace where a significant portion of the business is conducted via the Internet. He plotted the location of each firm with a .com Internet address and found that San Francisco, New York, and Los Angeles are the leading centres for Internet content in the United States with regard to absolute size and degree of specialization. ${ }^{17}$

The second method looks at the locations of the dominant firms in e-commerce. Again, Zook (2000, 2001) finds the top Internet companies based on electronically generated sales and other means and their location. His analysis shows San Francisco, New York, and Los Angeles as dominant in e-commerce, with Boston and Seattle ranking $4^{\text {th }}$ and $5^{\text {th }}$. When measured on a scale relative to the number of Fortune 1000 companies located in the region, his results indicate greater activity on the coasts (especially the West coast) with many Midwestern cities such as Detroit, Omaha, Cincinnati, and Pittsburgh lagging.

\section{Diffusion of advanced Internet access}

Internet connection generally comes in two forms: (1) dial-up (technology now behind the frontier); and (2) broadband (the new frontier technology).

\section{Provision and adoption}

While dial-up connection has moved past the frontier stage and is approaching saturation point in the United States, broadband access is still at the frontier. For a few

years it was far from ubiquitous, though that is changing as of this writing. ${ }^{18}$ However, 
as the volume and complexity of traffic on the Internet increases dramatically each year, the value of high-capacity and universal 'always on' broadband service is constantly increasing. Furthermore, broadband access will enable providers to offer a wider range of bundled communications services (for example, telephone, email, Internet video, etc.) as well as promote more competition between physical infrastructure providers already in place.

In the earliest years of diffusion to households - that is, prior to 2003 - the diffusion of broadband Internet access was very much supply-driven in the sense that supply-side issues were the main determinants of Internet availability and, hence, adoption. Cable firms and telephone firms needed to retrofit existing plant, and this constrained availability in many places. In these years the spread of broadband service was much slower and less evenly distributed than that of dial-up service. Highly populated areas were more profitable due to economies of scale and lower last mile expenses. As building has removed these constraints, demand-related factors - such as price, speed, and reliability - should play a more significant role in determining the margins between who adopts and who does not.

As of October 2003, 37.2 per cent of Internet users possessed a high-speed connection; the dominant types of broadband access were cable modems and xDSL. In addition, broadband penetration has been uneven, as 41.2 per cent of urban and 41.6 per cent of central city households with Internet access used broadband compared to a rate of only 25.3 per cent for rural households. Consistent with the supply-side issues, the FCC estimates that high-speed subscribers were present in 97 per cent of the most 
densely populated zip codes at the end of 2000 , whereas they were present in only 45 per cent in the zip codes with the lowest population density (NTIA 2002). Research by Prieger (2003) shows that high speed access and rural location are negatively correlated even after controlling for demographic variables, lending further support to the argument that the supply side is driving lower rural broadband adoption.

Most of the additional empirical evidence comes from these earliest years. For example, Augereau and Greenstein (2001) analyse the evolution of broadband provision and adoption by looking at the determinants of ISP's upgrade decisions. Although their analysis only looks at upgrades from dial-up service to 56K modem or ISDN service occurring by 1997, it addresses issues related to the provision of high-speed service and warrants mention as an empirical paper with the earliest evidence on ISP upgrade behaviour. In their model, they look for firm-specific factors and location-specific factors that affect firms' choices to offer more advanced Internet services. Their main finding is that 'the ISPs with the highest propensity to upgrade are the firms with more capital equipment and the firms with propitious locations' Augereau and Greenstein 2001: 1099). The most expansive ISPs locate in urban areas. They further argue that this could lead to inequity in the quality of supply between ISPs in high-density and lowdensity areas.

Grubesic and Murray (2002) look at differences in xDSL access for different regions in Columbus, Ohio. They point out that xDSL access can be inhibited for some consumers due to the infrastructure and distance requirements. The maximum coverage radius for $\mathrm{xDSL}$ is approximately 18,000 feet from a central switching office (CO), 
which is a large, expensive building. ${ }^{19}$ Furthermore, the radius is closer to 12,000 feet for high-quality, low-interruption service. Therefore, those living beyond this radius from the COs already built before xDSL was available, will more likely suffer from lack of service. As a counterintuitive result, such affluent areas as Franklin County in Ohio might lack high-speed access, which is contrary to the usual notion of there being a socioeconomic digital divide (Grubesic and Murray 2002). However, this does give more insight into why many rural residents (those living in places with more dispersed populations) might also lack high-speed access.

Gillett and Lehr (1999) compiled a database of communities in the United States where cable modem service is offered, and linked it to county-level demographic data. They found that broadband access is not universal. Only 43 per cent of the population lives in counties with available cable modem service. ${ }^{20}$ Broadband access is typically available in counties with large populations, high per capita income, and high population density; and there is a notable difference in the strategies of cable operators, with some being more aggressive than others.

In a very data-intensive study, Gabel and Kwan (2001) examine deployment of DSL services at central switches throughout the United States and provide a thorough census of upgrade activity at switches. They examine the choice of providers to deploy advanced technology - to make broadband services available to different segments of the population. The crucial factors in the decision to offer service are listed as: (1) cost of supplying the service; (2) potential size of the market; (3) cost of reaching the Internet backbone; and (4) regulations imposed on Regional Bell Operating Companies 
(RBOCs). ${ }^{21}$ They find that advanced telecommunications service is not being deployed in low-income and rural areas.

In summary, even before considering the impact of geographic dispersion on demand, the issues involved in the cost of supply guaranteed that the diffusion process of broadband would differ from dial-up. The earliest broadband ISPs, primarily cable companies and telephone companies, found highly dense areas more profitable due to economies of scale in distribution and lower expenses in build-out. Moreover, the buildout and retrofit activities for broadband are much more involved and expensive than was required for the build-out of dial-up networks. So within urban areas, there was uneven availability during the earliest years of the build-out.

The underlying economic situation has shaped this outcome. As long as prices for broadband are much higher than for dial-up, users face a price/quality trade-off, and different preferences over that trade-off shape the margin between adopter and nonadopter. If prices decline and become much closer to dial-up prices, then broadband's superior qualities should diminish the importance of that trade-off. In addition, providers of broadband may put together bundles of services (for example, voice, video, and Internet service) that have marketing appeal. Finally, and more speculatively, if a low-cost wireless solution for providing high-bandwidth applications emerges, then it may have features that might induce adoption where none has yet occurred. For a number of years one should expect next generations of Internet access to grow primarily by taking market share from dial-up, and secondarily by inducing first time adoption. There is little evidence to suggest that broadband will induce anything other than slow 
adoption by households who had not experienced the Internet by 2003 .

\section{Rural versus urban divides}

We can make several key observations concerning a geographical divide. First, a divide for basic dial-up Internet services is generally nonexistent, or, at worse, it is relegated to a very small part of the population. Due to the preexisting telephone service infrastructure, the cost of provision is relatively low; thus, we see over 92 per cent of households just a local call away from Internet connection. Furthermore, as of 2001, 52.9 per cent of rural residents were using the Internet, not much lower than the national average of 57.4 per cent (NTIA 2002).

Businesses participate at high rates, over 90 per cent for medium and large establishments (over 100 employees). While we do see lower basic participation rates in rural areas, this essentially is due to the type of industries we find there (that is, industries deriving less relative benefit from Internet connection). Thus, in this particular case, we see that it is not necessarily availability of Internet access, but largely the private incentives of the adopters (commercial businesses) that is determining the adoption rate.

Augereau and Greenstein (2001) warn of the possibility of the divide in availability worsening as large firms in large cities continue to upgrade their services rapidly while smaller firms in smaller cities move forward more slowly. Now that basic service is available almost everywhere in the country, the real issue of concern is the evolution of quality of service geographically, as well as value per dollar. Several 
authors warn that we may be headed down a road of bifurcation where large urban areas get better service at a faster pace, while smaller cities and urban areas fall behind. Greenstein (2000a: 408) suggests that urban areas get more new services due to two factors: “(1) increased exposure to national ISPs, who expand their services more often; and (2) the local firms in urban areas possess features that lead them to offer services with propensities similar to the national firms."

Along a different line of argument, Strover (2001) arrives at a similarly pessimistic assessment, one shared by many observers. ${ }^{22}$ She points out that the cost structure for ISPs is unfavourable because of their dependence on commercial telecommunications infrastructure providers, which are reluctant to invest in rural areas due to the high costs necessary to reach what often are relatively few customers. A lack of competition in rural areas among telephone service providers serves to exacerbate the low incentives. Furthermore, the fact that the economics of small cities are shaped more by the private sector than government initiatives, makes small cities less prone to initiating plans to develop telecommunications (Alles, Esparza, and Lucas 1994).

Many studies place a much greater emphasis on other variables along which they find the divide is much more pronounced. Hindman (2000) suggests that there is no strong evidence of a widening gap between urban and rural residents' use of information technologies, but that such predictors as income, education, and age have become even more powerful in predicting usage over the years (specifically from 1995 to 1998). 
Forman, Goldfarb, and Greenstein (2002, 2003a,b) find that, as of December 2000, 12.6 per cent of establishments engage in some form of Internet enhancement activities. Furthermore, they find much higher enhancement adoption rates in large cities (consolidated metropolitan statistical areas) as the top ten ranges from Denver at 18.3 per cent to Portland at 15.1 per cent. In addition, enhancement adoption rates in large urban counties (metropolitan statistical areas) is 14.7 per cent, while that of small counties is only 9.9 per cent on average. However, they also find that the industries of "management of companies and enterprises" (NAICS 55) and "media, telecommunications, and data processing" (NAICS 51) had enhancement adoption rates of 27.9 per cent and 26.8 per cent, respectively - rates far exceeding all other industries. ${ }^{23}$ This strongly points to the idea that geographical differences may largely be explained by the preexisting geographical distribution of industries.

\section{Overview}

\section{What happened during the first wave of diffusion?}

It was unclear at the outset which of several potential maturation processes would occur after commercialization. If advancing Internet infrastructure stayed exotic and difficult to use, then its geographic distribution would depend on the location of the users most willing to pay for infrastructure. If advancing Internet infrastructure became less exotic for a greater number of users and vendors, then commercial maturation would produce geographic dispersion over time, away from the areas of early experimentation.

Similarly, as advanced technology becomes more standardized, it is also more easily serviced in outlying areas, again contributing to its geographic dispersion. 
As it turned out, the first wave of the diffusion of the Internet (from 1995 to 2000) did not follow the most pessimistic predictions. The Internet did diffuse to urban areas with their complementary technical and knowledge resources, but the location of experiments was necessarily temporary, an artifact of the lack of maturity of the applications. As this service matured - as it became more reliable and declined in price so that wider distribution became economically feasible - the geographic areas that were early leaders in technology lost their comparative lead or ceased to be leaders. As such, basic ISP technology diffused widely and comparatively rapidly after commercialization. On-the-margin users in urban areas had a better experience than users in rural areas, but many of these differences arose for straightforward economic reasons, such as the cost of provision and the lack of economies of scale brought about by thin demand.

Open questions remain as the next wave proceeds. There is little experience with uncoordinated commercial forces developing a high-speed communication network with end-to-end architecture. This applies to the many facets that make up advanced telecommunications services for packet switching, such as switching using frame relay or Asynchronous Transfer Mode, as well as Synchronous Optical Network equipment or Optical Carrier services of various numerical levels (Noam 2001).

The spread of broadband service has been seemingly slower and almost certainly much less evenly distributed than that of dial-up. This is not a surprise once their basic economics is analysed and it may be an artifact of early limitations on availability. The broadband ISPs find highly dense areas more profitable due to economies of scale in 
distribution and lower expenses in build-out. Moreover, the build-out and retrofit activities for broadband are much more involved and expensive than was required for the build-out of the dial-up networks.

\section{Open questions about the second wave}

How will the Internet's geographic characteristics shape economic growth during the second wave of diffusion? The answer is not clear for a variety of reasons. First, it is not clear whether new technologies for delivering the Internet will alter the bilateral relationship between geography and the Internet. For example, will Internet connection via satellite emerge as the connection of choice, and if so, how much would this dampen the argument that location matters? Will another fixed wireless solution emerge for delivery of high-speed data services, and will it exhibit low enough economies of scale to spread to suburban areas? Second, and perhaps more speculatively, the Internet will affect the diffusion of other new products. As the majority of American homes become hard-wired, how drastic will the effect be on local media, such as local newspapers (see, for example, Chyi and Sylvie 2001)? If individuals can access any radio station in the country at any time, how can all incumbent stations possibly stay in existence? These were mostly rhetorical questions about hypothetical scenarios during the earliest years of the Internet's diffusion, but have become less so with increasing numbers of Internet users. The Internet has diffused to a sufficiently large population that researchers have begun to accumulate evidence based on actual firm behaviour (for example, see Ting and Wildman 2002).

Third, it is not clear whether the digital divide will accelerate or decelerate, as 
new technologies diffuse on the existing network. Consider the following: use of some peer-to-peer technologies, such as ICQ and Napster and Skype, spread very fast worldwide because these were nested within the broader use of the Internet at the time. Was their speed of adoption exceptional, a by-product of the early state of the commercial Internet, or something we should expect to see frequently? There are related questions about the spread of new technologies supporting improvements in the delivery of Internet services. Will the diffusion of IP.v6 occur quickly because its use is nested within the structure of existing facilities? Will various versions of XML spread quickly or slowly due to the interrelatedness of all points on the Internet? What about standards supporting IP telephony? Will 802.11b (aka Wi-Fi) diffuse to multiple locations because it is such a small scale technology, or will its small scale interfere with a coordinated diffusion?

As we speculate about future technologies, two overriding lessons from the past shape our thinking. First, once the technology was commercialized, private firms tailored it in multiple locations in ways that nobody had foreseen. Indeed, the eventual shape, speed, growth, and use of the commercial Internet was not foreseen within government circles (at NSF), despite (comparatively) good intentions and benign motives on the part of government overseers, and despite advice from the best technical experts in the world. Second, Internet infrastructure grew because it is malleable, not because it was technically perfect. It is better thought of as a cheap retrofit on top of the existing communications infrastructure. No single solution was right for every situation, but a TCP/IP solution could be found in most places. The US telephone system provided fertile ground because backbone used existing infrastructure when possible. What 
existing infrastructure will the next generation of Internet use?

\section{References}

Alles, P., Esparza, A., and Lucas, S. (1994). 'Telecommunications and the Large CitySmall City Divide: Evidence from Indiana cities'. Professional Geographer, 46: 307-

16.

Atrostic, B. K. and Nguyen, S.V. (2002). 'Computer Networks and US Manufacturing Plant Productivity: New Evidence from the CNUS Data'. Working Paper \#02-01, Center for Economic Studies, US Census Bureau, Washington, DC.

Augereau, A. and Greenstein, S. (2001). 'The Need for Speed in Emerging

Communications Markets: Upgrades to Advanced Technology at Internet Service

Providers'. International Journal of Industrial Organization, 19: 1085-1102.

Bauer, J. M. (2005). 'Unbundling Policy in the United States: Players, Outcomes and Effects'. Communications and Strategies, 57: 59-82.

Bertot, J. and McClure, C. (2000). Public Libraries and the Internet, 2000, Report prepared for National Commission on Libraries and Information Science, Washington, DC, http://www.nclis.gov/statsurv/2000plo.pdf.

Boardwatch Magazine (Various years). Directory of Internet Service Providers, Littleton, CO.

Bresnahan, T. and Greenstein, S. (2001). 'The Economic Contribution of Information Technology: Towards Comparative and User Studies'. Evolutionary Economics, 11: 95118.

Bresnahan, T. and Trajtenberg, M. (1995). 'General Purpose Technologies: "Engines of Growth"? Journal of Econometrics, 65(1): 83-108. 
Castells, M. (2002). The Internet Galaxy, Reflections on the Internet, Business and Society. Oxford: Oxford University Press.

Chyi, H. I. and Sylvie, G. (2001). 'The Medium Is Global, the Content Is Not: The Role of Geography in Online Newspaper Markets'. Journal of Media Economics, 14(4): 23148.

Cortada, J. W. (1996). Information Technology as Business History: Issues in the History and Management of Computers. Westport, CT: Greenwood Press.

Crandall, R. W. and Alleman, J. H. (2002). Broadband: Should We Regulate HighSpeed Internet Access? Washington, DC: AEI-Brookings Joint Center for Regulatory Studies.

Dodge, M. and Kitchin, R. (2001a). Atlas of CyberSpace. London: Addison Wesley. —(2001b). Mapping CyberSpace. London: Routledge.

Downes, T. and Greenstein, S. (1998). 'Do Commercial ISPs Provide Universal Access?' in S. Gillett and I. Vogelsang (eds) Competition, Regulation and Convergence: Current Trends in Telecommunications Policy Research. Mahwah, NJ: Lawrence Erlbaum Associates, 195-212.

_-(2002) 'Universal Access and Local Internet Markets in the U.S.' Research Policy, 31: $1035-52$.

Forman, C. (2005). ‘The Corporate Digital Divide: Determinants of Internet Adoption'. Management Science, 51(4): 641-54.

Forman, C., Goldfarb, A., and Greenstein, S. (2002). 'Digital Dispersion: An Industrial and Geographic Census of Commercial Internet Use'. Working Paper, NBER, Cambridge, MA.

—(2003a). 'The Geographic Dispersion of Commercial Internet Use', in S. Wildman 
and L. Cranor (eds) Rethinking Rights and Regulations: Institutional Responses to New Communication Technologies. Cambridge, MA: MIT Press, 113-45.

— (2003b). 'Which Industries use the Internet?', in M. Baye (ed.) Organizing the New Industrial Economy. Amsterdam: Elsevier, 47-72.

- (2005). 'How did Location Affect Adoption of the Internet by Commercial Establishments? Urban Density versus Global Village'. Journal of Urban Economics, 58(3): 389-420.

Gabel, D. and Kwan, F. (2001). 'Accessibility of Broadband Communication Services by Various Segments of the American Population', in B. Compaine and S. Greenstein (eds) Communications Policy in Transition: The Internet and Beyond. Cambridge, MA: MIT Press, 295-320.

Garcia, D. L. (1996). 'Who? What? Where? A Look at Internet Deployment in Rural America'. Rural Telecommunications, Nov./Dec.: 25-9.

Gillett, S. E., and Lehr, W. (1999). ‘Availability of Broadband Internet Access: Empirical Evidence', http://itel.mit.edu/itel/docs/MISC/LehrGillettTPRC99_0523.doc, accessed 17 Mar. 06.

— Telecommunications Policy 28: 537-58.

Goolsbee, A. and Klenow, P. (1999). 'Evidence on Learning and Network Externalities in the Diffusion of Home Computers'. Working Paper \# 7329, NBER, Cambridge, MA. Gorman, S. P. and Malecki, E. J. (2000). 'The Networks of the Internet: An Analysis of Provider Networks in the USA'. Telecommunications Policy, 24(2): 113-34.

Greenstein, S. (2000a). 'Building and Delivering the Virtual World: Commercializing Services for Internet Access'. The Journal of Industrial Economics, 48(4): 391-411. 
— (2000b). 'Empirical Evidence on Commercial Internet Access Providers' Propensity to Offer new Services', in B. Compaign and I. Vogelsang (eds) The Internet Upheaval, Raising Questions and Seeking Answers in Communications Policy. Cambridge, MA: MIT Press, 253-76.

—(2005). 'The Economic Geography of Internet Infrastructure in the United States', in M. Cave, S. Majumdar, and I. Vogelsang (eds) Handbook of Telecommunications Economics, Vol. II. Amsterdam: Elsevier Publishing, 289-374.

— and Mazzeo, M. (2006 forthcoming). 'Differentiated Entry into Competitive Telephony,' Journal of Industrial Economics.

Grubesic, T. H. and Murray, A. T. (2002). 'Constructing the Divide: Spatial Disparities in Broadband Access'. Papers in Regional Science, 81(2): 197-221.

— and O'Kelly, M. E. (2002). 'Using Points of Presence to Measure Accessibility to the Commercial Internet'. Professional Geographer, 54(2): 259-78.

Hargettai, E. (2003). 'The Digital Divide and What To Do About It', in D. C. Jones (ed.) The New Economy. San Diego, CA: Academic Press, 822-38.

Hindman, D. B. (2000). ‘The Rural-Urban Digital Divide'. Journalism and Mass Communication Quarterly, 77(3): 549-60.

Jimeniz, E. and Greenstein, S. (1998). 'The Emerging Internet Retailing Market as a Nested Diffusion Process'. International Journal of Innovation Management, 2(3): 281308.

Kahn, R. (1995). 'The Role of Government in the Evolution of the Internet,' in National Academy of Engineering (ed.) Revolution in the U.S. Information Infrastructure. Washington, DC: National Academy Press, 13-24.

Kende, M. (2000). 'The Digital Handshake: Connecting Internet Backbones,' Working 
Paper No. 32., Federal Communications Commission, Office of Planning and Policy, Washington, DC.

Kitchin, R. M. (1998). 'Towards Geographies of Cyberspace'. Progress in Human Geography, 22(3): 385-406.

Kolko, J. (2000). 'The Death of Cities? The Death of Distance? Evidence from the Geography of Commercial Internet Usage', in I. Vogelsang and B. Compaine (eds) The Internet Upheaval: Raising Questions, Seeking Answers in Communications Policy. Cambridge, MA: MIT Press, 73-98.

_-(2002). 'Silicon Mountains, Silicon Molehills, Geographic Concentration and Convergence of Internet Industries in the U.S.' Economics of Information and Policy. 14(2): 211-32.

Malecki, E. J. (2002). 'The Economic Geographic of the Internet's Infrastructure'. Economic Geography, 78(4): 399-424.

— and Gorman, S. (2001). 'Maybe the Death of Distance, But not the End of Geography: The Internet as a Network', in T. Leinbach and S. Brunn (eds) Worlds of ECommerce: Economic, Geographical and Social Dimensions. New York: John Wiley and Sons, 87-105.

Moss, M. L. and Townsend, A. M. (1999). 'How Telecommunications Systems are Transforming Urban Spaces', in J. O. Wheeler and Y. Aoyama (eds) Cities in the Telecommunications Age. New York: Routledge, 31-41.

- (2000). 'The Internet Backbone and the American Metropolis'. Information Society, 16(1): 35-47.

- (2002). 'The Role of the Real City in Cyberspace: Measuring and Representing Regional Variations in Internet Accessibility', in D. Janelle and D. Hodge (eds) 
Information, Place, and Cyberspace. Berlin: Springer Verlag, 171-86.

Mowery, D. C. and Simcoe, T. S. (2002). 'The Origins and Evolution of the Internet,' in R. Nelson, B. Steil, and D. Victor (eds) Technological Innovation and Economic

Performance. Princeton, NJ: Princeton University Press, 229-64.

NTIA (National Telecommuncations and Information Administration) (2004). 'A

Nation Online: Entering the Broadband Age', http://www.ntia.doc.gov/reports.html.

— (2002). 'A Nation Online: How Americans Are Expanding Their Use Of The

Internet', http://www.ntia.doc.gov/reports.html, assessed 17 Mar. 06.

_ (1998). 'Falling Through the Net II: New Data on the Digital Divide',

http://www.ntia.doc.gov/reports.html, assessed 17 Mar. 06.

—(1997). 'Falling Through the Net: Defining the Digital Divide',

http://www.ntia.doc.gov/reports.html, assessed 17 Mar. 06

- (1995). 'Falling Through the Net: A Survey of the 'Have Nots' in Rural and Urban

America', http://www.ntia.doc.gov/reports.html, assessed 17 Mar. 06.

New Paradigm Resources Group (2000). CLEC Report, Chicago, IL.

Noam, E. (2001). Interconnecting the Network of Networks. Cambridge, MA: MIT

Press.

Nuechterlein, J. E. and Weiser, P. J. (2005). Digital Crossroads: American

Telecommunications Policy in the Internet Age, Cambridge, MA: MIT Press.

Oxman, J. (1999). 'The FCC and the Unregulation of the Internet,' Working paper 31, Federal Communications Commission, Office of Planning and Policy, Washington, DC.

Parker, E. B. (2000). 'Closing the Digital Divide in Rural America'.

Telecommunications Policy, 24(4): 281-90.

Porter, M. (2001). 'Strategy and the Internet'. Harvard Business Review. 79(3): 62-78. 
Premkumar, G. and Roberts, M. (1999). ‘Adoption of New Information Technologies in Rural Small Businesses'. Omega-International Journal of Management Science, 27(4): 467-84.

Prieger, J. E. (2003). 'The Supply Side of the Digital Divide: Is There Equal Availability in the Broadband Internet Access Market?' Economic Inquiry, 41(2): 34663.

Prince, J. (2005). 'Measuring the Digital Divide: Structural Estimation of the Demand for Personal Computers', mimeo, Cornell University.

Rogers, E. M. (1995). Diffusion of Innovations. New York: Free Press.

Rosston, G. and Wimmer, B. (2001). “"From C to Shining C” Competition and CrossSubsidy in Communications', in B. Compaine and S. Greenstein (eds) Communications Policy in Transition: The Internet and Beyond. Cambridge, MA: MIT Press, 241-64. Sinai, T. and Waldfogel, J. (2004). 'Geography and the Internet: Is the Internet a Substitute or a Complement for Cities?' Journal of Urban Economics 56(1): 1-24. Stafford, T. F. (2003). 'Differentiating between Adopter Categories in the Uses and Gratifications for Internet Services', IEEE Transactions on Engineering Management, 50(4): 427-35.

Strover, S. (2001). 'Rural Internet Connectivity'. Telecommunications Policy, 25(5): $331-47$.

Strover, S. and Berquist, L. (2001). 'ping Telecommunications Infrastructure: State and Local Policy Collisions', in B. Compaine and S. Greenstein (eds) Communications Policy in Transition: The Internet and Beyond. Cambridge, MA: MIT Press, 221-40. Strover, S., Oden, M., and Inagaki, N. (2002). 'Telecommunications and Rural Economies: Findings from the Appalachian Region', in L. F. Cranor and S. Greenstein 
(eds) Communication Policy and Information Technology: Promises, Problems,

Prospects. Cambridge, MA: MIT Press, 317-46.

Ting, C. and Wildman, S. (2002) 'The Economics of Internet Radio,' paper presented at the $30^{\text {th }}$ Telecommunications Policy Research Conference, Alexandria, VA, 29 Sept. Townsend, A. M. (2001a). 'Network Cities and the Global Structure of the Internet'. American Behavioral Scientist, 44(10): 1697-716.

—(2001b). 'The Internet and the Rise of the New Network Cities, 1969-1999'.

Environment and Planning B-Planning \& Design, 28(1): 39-58.

USDA (US Department of Agriculture) (2000) Advanced Telecommunications in Rural America, The Challenge of Bringing Broadband Communications to All of America, http://www.ntia.doc.gov/reports/ruralbb42600.pdf vanDijk, J. A. G. M. (2005). The Deepening Digital Divide: Inequality in the Information Society. Thousand Oaks, CA: Sage Publications.

Warf, B. (2001). 'Segue Ways into Cyberspace: Multiple Geographies of the Digital Divide'. Environment and Planning B-Planning and Design, 28(1): 3-19.

Weinberg, J. (1999). 'The Internet and Telecommunications Services, Access Charges, Universal Service Mechanisms, and Other Flotsam of the Regulatory System', in S. Gillett and I. Vogelsang (eds) Competition, Regulation and Convergence: Current Trends in Telecommunications Policy Research. Mahwah, NJ: Lawrence Erlbaum Associates, 297-316.

Werbach, K. (1997). A Digital Tornado: The Internet and Telecommunications Policy. Working Paper 29, Federal Communication Commission, Office of Planning and Policy, Washington, DC.

Woroch, G. (2001). 'Local Network Competition', in M. Cave, S. Majumdar, and I. 
Vogelsang (eds) Handbook of Telecommunications Economics. Amsterdam: Elsevier Publishing, 642-716.

Zook, M. A. (2000). 'The Web of Production: the Economic Geography of Commercial Internet Content Production in the United States'. Environment and Planning A, 32(3): $411-26$.

(2001). 'Old Hierarchies or New Networks of Centrality? The Global Geography of the Internet Content Market'. American Behavioral Scientist, 44(10): 1679-96. 
${ }^{1}$ Northwestern University, Department of Management and Strategy, Kellogg School of Management, and Cornell University, Department of Applied Economics and Management, respectively. We thank the Kellogg School of Management for financial support. We thank an anonymous reviewer and the editors for extensive comments. All errors contained here are our responsibility.

${ }^{2}$ For more on the diffusion of PCs, see Goolsbee and Klenow (1999), United States Department of Agriculture (2000), or NTIA (1995, 1997, 1998, 2002).

${ }^{3}$ As of 2003, approximately $1 \%$ of households accessed the Internet using a mobile telephone or some other home Internet access device. More than this, only $14.2 \%$ of Internet users did not have home access, further highlighting the strong relationship between Internet use and home adoption (NTIA, 2004).

${ }^{4}$ These are the one-time costs of learning how to use a PC and all its peripherals.

${ }^{5}$ For the full historical trend, see also NTIA $(1995,1997,1998)$.

${ }^{6}$ This is a large topic and outside the scope of this review. See, for example, Hargettai (2003) or vanDijk (2005).

${ }^{7}$ See, also, Atrostic and Nguyen (2002), who look at establishments in manufacturing. To the extent that they examine adoption, their study emphasizes how the size of establishments shapes the motives to adopt networking for productivity purposes.

${ }^{8}$ For a comprehensive review of the literature, see Woroch (2001).

${ }^{9}$ The FCC's decision was made many years earlier for many reasons, and extended to ISPs in the mid-1990s with little notice at the time, since most insiders did not anticipate the extent of the growth that would arise. As ISPs grew in geographic coverage and revenues and threatened to become competitive voice carriers, these 
interconnection regulations came under more scrutiny (Werbach 1997, Kende 2000, Weinberg 1999).

${ }^{10}$ See Crandall and Alleman (2002).

${ }^{11}$ Some ISPs operated as CLECs and vice versa, but many did not. This is a complex topic, still changing as of this writing. See www.alts.org, New Paradigm Resources Group (2000), or Greenstein and Mazzeo (2005).

${ }^{12}$ For a review of the determinants of pricing within states, see Rosston and Wimmer (2001).

${ }^{13}$ This is a complex topic that necessarily strays into matters outside the scope of this review. For extensive description and analysis of these disputes and their resolution, see e.g., Bauer (2005) or Nuechterlein and Weiser (2005).

${ }^{14}$ For example, Greenstein and Mazzeo (forthcoming) find that most CLECs explicitly targeted their services at businesses and few CLECs offered only household service. In low density areas the CLECs were largely existing phone companies who tried to cream skim business customers in neighbouring small towns. With only a few exceptions, in the major urban areas those CLECs that targeted households did so in conjunction with their business services and only when the costs of doing so were not cost-prohibitive, such as in a high density location like Manahattan, or in downtown Chicago, or Boston, or San Francisco.

${ }^{15}$ For a variety of perspectives, see Kitchin (1998), Moss and Townsend (1999), Dodge and Kitchin (2001a, 2001b), Castells (2002), Malecki and Gorman (2001), Gorman and Malecki (2002) and reviews in Malecki (2002) and Greenstein (2005).

${ }^{16}$ See, also, Kolko (2002). 
${ }^{17}$ Degree of specialization is measured by relating the number of .com domains in a region relative to the total number of firms in a region to the number of .com domains in the United States relative to the total number of firms in the United States (Zook 2000).

18 Broadband is defined by theFCC as the capability of supporting at least $200 \mathrm{Kbps}$ in at least one direction (supplier and/or consumer), http://www.fcc.gov.

${ }^{19}$ This is the non-amplified radius; with amplifiers the signal could reach further. However, the 18,000 feet only applies to service of up to $1.5 \mathrm{Mbps}$; for higher speeds, the radius is even more limited. For example, for speeds of $8 \mathrm{Mbps}$, the limit is 9,000 feet and for VDSL, which could supply up to $55 \mathrm{Mbps}$, the limit is a mere 1,000 feet. ${ }^{20}$ They point out that this population is actually closer to $27 \%$ (as was stated by Kinetic Strategies), but explain that their data are not fine enough to show this measurement. ${ }^{21}$ Data were obtained concerning wire centres; also data on DSL and cable modem service availability were collected via web sites and calling service providers. They supplemented it with Census data.

${ }^{22}$ See also Garcia (1996), Parker (2000), Hindman (2000).

${ }^{23}$ NAICS stands for the North American Industry Classification System. 